\title{
Exercise for the older woman: choosing the right prescription
}

\author{
J E Taunton, A D Martin, E C Rhodes, L A Wolski, M Donelly, J Elliot
}

Allan McGavin Sports Medicine Centre and School of Human

Kinetics

JE Taunton

School of Human Kinetics, University of British Columbia, Canada

AD Martin

EC Rhodes

LA Wolski

STAT Unit, Vancouver Hospital and Health

Sciences Centre,

Vancouver, British

Columbia, Canada

M Donelly

J Elliot

Correspondence to:

Dr Jack E Taunton, Alan

McGavin Sports Medicine

Centre, John Owen Pavilion,

3055 Wesbrook Mall,

Vancouver, British Columbia

V6T 1Z3, Canada.

Accepted for publication

17 December 1996

\begin{abstract}
Many elderly women in industrially developed countries are at, or near to, functionally important strength related thresholds and so have either lost, or are in danger of losing, the ability to perform some important everyday tasks. The increased rate of healthcare expenditure due to loss of physical function is a major economic issue. Even though women make up most of the senior population, little current research on the impact of physical activity on strength and function in elderly people has included women. Elderly women typically have more barriers to participation in physical activity than do other groups and because of decreased participation, may possibly experience higher disability rates. Physical activity in old age may delay the progression of osteoporosis and is of paramount importance for maintaining the functional abilities needed to carry out daily tasks. Current research on exercise and the elderly population suggests that strength training may be the exercise mode of choice for maintenance of strength, physical function, bone integrity, and psychosocial health. This review summarises recent research on the impact of strength training on the fitness and health of elderly women and highlights considerations and potential barriers to physical activity that must be taken into account when planning exercise programmes for them.

(Br F Sports Med 1997;31:5-10)
\end{abstract}

Keywords: elderly women; strength training; physical function; exercise.

Many industrially developed countries are confronted with the practical problems of a rapidly expanding geriatric population. Aging and a subsequent loss of strength will have a pronounced effect on the capacity of this population to lead viable and independent lives. About $10 \%$ of non-disabled community dwelling adults aged 75 or older lose independence in basic activities of daily living each year. ${ }^{1}$ This functional dependence is associated with increased mortality ${ }^{2}$ and leads to additional adverse outcomes, such as admission to hospi- tal, nursing home placement, and greater use of formal and informal home services. ${ }^{3-5}$ Strategies for reducing the frequency of this common cause of morbidity and mortality are needed.

The increased rate of healthcare expenditure due to loss of physical function is a major economic issue in industrially developed countries. For example, in Canada, $40 \%$ of current healthcare expenditures are devoted to treatment of the older adult population. ${ }^{6}$ However, the most important focus of any geriatric programme is not to reduce healthcare cost, but rather to maintain physical independence as this has been shown to increase the wellbeing and quality of life of senior citizens. ${ }^{78}$

There is a parallel between inactivity and aging; inactivity is, to a great degree, responsible for the physiological decline attributed to the aging process, ${ }^{9-11}$ a decline that is more apparent in women than men. ${ }^{12}$ Increasing evidence shows that some of the age related declines in physiological and cognitive function may be attenuated, or even reversed, by regular physical activity, thus preserving functional independence. ${ }^{13}$

Women outlive men by seven or eight years which means that after the age of $80,88 \%$ of women live on their own and make up most of our elderly population. A recent study by Van Den Hambergh et $a l^{14}$ found that elderly widowed or unmarried women tend to be less active than married women of the same age and that most elderly women in our society are not physically active enough to maintain physical independence. Disability is also disproportionately more common in women. ${ }^{315}$ Therefore, women should be the initial target for intervention to help maintain the ability to perform everyday tasks and activities. ${ }^{16}$ It is essential that exercise scientists and other healthcare professionals understand the interplay between decreased physical activity and increased age, particularly in women.

Unfortunately, much of the current data on the impact of exercise on strength and function in elderly people include a minimal number of female subjects in the upper age ranges. ${ }^{17}$ This group typically exhibits a lack of familiarity with exercise and low functional capacity, and may possibly experience an acceleration of the age related declines in functional capacity. ${ }^{18}$ It 
is imperative that the barriers to exercise that inhibit elderly women from participating in exercise be identified and strategies for promoting physical activity in these same women be developed. Current research in this area has suggested that maintenance of strength and of bone mineral density can help to maintain physical function. The purpose of this review is to highlight the research focusing on the impact of exercise on elderly women. In particular, the effects of strength training exercise on their ability to function, strength, bone mineral density, and psychosocial health will be discussed.

\section{Exercise and strength}

Although aging is a universal biological phenomenon, its various morphological and physiological manifestations make it impossible to provide a single process or theory which adequately describes it. As time progresses, the cumulative biological changes that occur in all species ultimately result in decreased ability to function in the environment. ${ }^{19}$ True age related declines include intrinsic impairments in cross bridges, changes in the concentrations of substances in the cytosol, ${ }^{11}$ loss of entire motor units, ${ }^{20}$ and a loss of muscle membrane excitability. ${ }^{21}$ Motor unit impairments from a decrease in the number of motor units, a decrease in the innervation ratio, or the cross sectional area of individual fibres, whole muscle atrophy, weakness, fatigue, and injury are evidenced by impaired mobility in the activities of daily living as well as an increased incidence of soft tissue injuries and falls. These age related deteriorations may be, in part, biologically inherited, but they may also be modified by environmental conditions such as nutrition, stress, and physical inactivity. ${ }^{22}$

The decline of muscle strength with age has been quantified as about $15 \%$ per decade after the age of about $60 .{ }^{23}$ Additionally, lower limb muscles seem to be more affected by aging than upper limb muscles. ${ }^{24}$ Increased sedentary activity and the lack of fast and forceful movements during standing and walking severely compromise the large muscles of the legs. However, this age related loss of muscle strength, which reduces the capacity for physical activity performance, can be slowed down or even reversed by resistance training, thereby possibly improving the quality of life for elderly people.

Females are weaker than males in overall body strength at all ages. ${ }^{25} \mathrm{~A}$ recent survey in the United States has shown that after the age of $74,66 \%$ of women cannot lift objects weighing more than $4.5 \mathrm{~kg} .{ }^{10}$ Young $^{26}$ found that the typical healthy 80 year old woman is at, or very near, the threshold value of quadriceps strength required to rise from a chair. Thus any reduction in strength may lead to loss of physical independence in activities of daily living and is also a risk factor for both falls and hip fractures.

Most studies concerning the adaptation of skeletal muscle to strength training in elderly people have been conducted on men. From the limited research that has been done on elderly women, there seems to be a positive relation between activity level and strength. ${ }^{27-30}$ Knee extension strength and walking speed were higher in a group of elderly (66-85 year old) physically trained women than in a group of age matched controls ${ }^{27}$ and elderly female athletes (endurance and strength) were found to have better muscle performance than age matched controls. ${ }^{28}$ However, training mode may have an impact on maintenance of strength in elderly people. Klitgaard et $a l^{11}$ reported superior muscle performance among elderly strength trained athletes when compared with endurance athletes or age matched untrained controls.

Although the differences between untrained and trained elderly women provide solid evidence that training can positively influence muscle performance and strength, of more interest to us is the impact of an exercise programme on the strength of previously inactive women as most elderly women in our society are not involved in physical activity. Recent research by our group showed that general land based and water based training programmes improved maximum aerobic power in elderly women (aged 65-75 years) but did not increase muscular strength, or change body composition. ${ }^{32}$ It was suggested that specific strength training programmes may be required to improve strength and balance in elderly women. Subsequent research by our team showed that a one year progressive resistance exercise programme in women aged 65-75 resulted in significant strength changes. ${ }^{33}$

Other strength training studies in elderly women have had mixed success in improving strength. Generally, programmes of longer duration have resulted in improvements in strength whereas those of shorter duration have produced equivocal results. For example, Morganti $e t a l^{34}$ trained 16 women twice a week at $80 \%$ of one repetition maximum for 12 months and found that one repetition maximum strength test scores improved $82 \%, 41 \%$, and $84 \%$ for the knee extensor, double leg press, and lateral pull down exercises respectively. They concluded that high intensity progressive resistance training resulted in substantial, continual increases in strength in postmenopausal women. Pyka et $a l^{35}$ studied 25 men and women who exercised three times a week for 12 months on a 12 exercise circuit at $75 \%$ of one repetition maximum. They found that average strength increased by $30 \%$ (hip extensors) to $97 \%$ (hip flexors) and found hypertrophy of both type 1 and type 2 fibres.

In strength training programmes of shorter duration, some researchers have shown improvements in strength after eight to 16 weeks of strength training, ${ }^{3637}$ whereas others found that strength training programmes of 18 weeks were not effective in inducing fibre transformation or hypertrophy in muscle fibres of healthy elderly women. ${ }^{38}$

The results of these studies suggest that training programmes for elderly women need to focus on longer durations than programmes designed for young adults. Because aging muscle adapts more slowly to stress, it is essential 
that elderly women are encouraged to begin a lifetime change in exercise patterns to maintain or increase strength. Training benefits such as increases in strength are lost with cessation of training. For most of the population, this means a decrease in physical fitness and limitations in physical activity. However, for elderly women, the loss of strength can mean the loss of physical function, independence, and mobility. Recently, Gill et al ${ }^{1}$ established a battery of simple functional tests that assess physical performance and identify subgroups of older persons who are at increased risk for functional dependence. This group found that in a community sample of adults 72 years of age and older, who were independent in activities of daily living, nearly $10 \%$ became dependent in one or more activities of daily living by one year. Thus the relation between increasing activity and maintenance of function becomes increasingly important as women age.

\section{Exercise and function}

Although it is inevitable that aging produces physiological change, some of the declines in physical and mental dexterity can be retarded through exercise. It is well documented that physical activity in old age can help to sustain muscle mass ${ }^{39} 40$ and bone density. ${ }^{41}$ It also helps to maintain other aspects of physical fitness such as maximal aerobic power, ${ }^{18}$ motor performance, ${ }^{42}$ grip strength, ${ }^{43}$ reaction time, ${ }^{44-46}$ and flexibility. ${ }^{47}$ However, the applicability of the improvements in the various components of fitness with functional ability remains unclear. Buchner and Wagner ${ }^{48}$ showed that impaired balance and decreased lower limb strength are important risk factors for the loss of physical function. Few researchers have attempted to correlate the benefits of exercise with improvements in the ability to carry out daily functional tasks. The risk factors that are generally assessed, such as smoking, hypertension, body mass index, and heart disease are not strong predictors of functional decline.

Simonsick et al ${ }^{30}$ examined the association between recreational physical activity among physically capable older adults and functional status, incidence of selected chronic conditions, and mortality over three and six years. They found that a moderate to high activity level (activity being vigorous exercise performed at least weekly or frequent walking) reduced the likelihood of developing limitations in physical functioning over three years, particularly in the areas of walking and doing heavy housework. Fitness level was not measured; however, it can reasonably be assumed that the fitness of the more active subjects was higher than that of the sedentary subjects. Thus increased fitness seems to decrease the risk of loss of function of activities of daily living.

In the past few years, researchers have been using training studies with elderly women in an effort to show a direct link between functional ability and fitness. The results have been very positive in that many have found that strength training improves functional ability in elderly people. For example, Fiatrone et $a l^{49}$ and
Sauvage $e t a l^{0}$ found that walking speed and stair climbing ability were positively related to muscle strength and were improved after strength conditioning in frail elderly subjects. Additionally, Hunter $e t a l^{36}$ found that women aged 60-77 and living independently, significantly improved their ability to rise from a chair and carry a box of groceries after 16 weeks of strength conditioning. They also showed significant increases in walking velocity even though walking was not part of the exercise programme. Furthermore, Connelly and Vandervoort ${ }^{37}$ found that strength as well as scores on functional tests such as self paced walking and timed up and go results improved significantly in 10 women, mean age 81.6 years, who completed an eight week strengthening programme.

The above studies certainly indicate that strength training programmes can help to maintain or even improve activities of daily living. However, Skelton et $a t^{11}$ found that a general strength training programme in women aged 75 to 93 years resulted in significant increases in strength and power, but only minimal improvements in functional ability. Further research by this group ${ }^{16}$ showed that strength training sessions that included the practice of functional tasks and mobility produced substantial increases in balance, strength, flexibility, and selected tests of functional mobility. It may be that strength training to maintain function needs to be very specific. That is, training programmes should focus on movements that are used in activities of daily living and not just general movement.

Whereas strength training has been shown to have a positive influence on function in elderly women, there is still research to be done. It remains unclear whether other forms of exercise that are popular with elderly women, such as walking, stretching, or pool exercises, will elicit the same improvements or maintenance of physical function as strength training. Clark $^{52}$ suggested that walking four to seven days a week may protect against lower body decline; however, other researchers have not been able to show improvements in strength, mobility, or function with walking ${ }^{534}$ or general land based or water based exercise programmes. ${ }^{32}$ However, general activity, although not improving physical function, may have a significant impact on the psychosocial health of elderly women.

\section{Psychological benefits of exercise}

There is evidence of a positive relation between level of activity and mental health. Involvement in physical activity may prevent the onset of mental health problems or may ameliorate such problems before they escalate to levels of clinical relevance. ${ }^{55}$ Exercise has been shown to help reduce the effects of insomnia, stress, depression, and chronic illness. It also plays a vital part in improved weight control, body image, and, especially in the case of the elderly population, independence. Physical activity can also provide an alternative to alcohol and substance misuse and may help patients who have mild to moderate depression. ${ }^{56}$ 
It is not known if an exercise programme will enhance psychological variables in women who are not experiencing defined mental health problems. Most research on the effects of exercise on mental health has used young and middle aged subjects or has been conducted in clinical settings. There is a paucity of research on the influence of exercise on the mental health of older healthy women. However, one study has shown that improvements in muscle strength as a result of strength training increased independence of elderly subjects and caused improvements in mental attitude. Bozoian and McAuley ${ }^{57}$ had 33 subjects, mean age 86.4 years complete a 10 week activity programme of either flexibility exercises or strength exercises. They found that the strength group significantly increased strength in the upper body compared with the flexibility group. Both exercise groups increased in positive effect and decreased in negative effect. The strength training group were significantly more satisfied with life than the flexibility subjects and also showed a significant improvement in their ability to carry out activities of daily living. Bravo et $a f^{8}$ also showed that self perceived health increased with weight bearing exercise in 124 osteopenic women aged 50-70 years.

Traditionally, women have had more barriers to physical activity than men-this is particularly true for elderly women. Many older women were raised in an era when vigorous exercise was not recommended for women. As women entered puberty, physical activity dropped dramatically as it was thought that exercise was not ladylike and would harm the reproductive organs. Additionally, marital status, socioeconomic status, and health problems may discourage elderly women from participating in physical activity. As a result many elderly women have never taken part in a regular exercise programme. A strength training study by our research team ${ }^{33}$ had a group of women aged 65 to 75 years participate in a supervised strength training programme for 12 weeks. The women then continued training on their own for a further nine months keeping log books of all of their workouts. All of the women completed the study and the attendance at the required number of workouts per week was close to $100 \%$ for all of the subjects. The study showed that with encouragement and support, older women can successfully maintain a strength training programme for many months without direct supervision.

The results of Bozoian and McAuley ${ }^{57}$ certainly suggest a positive impact of strength training in elderly people. Furthermore, it seems that elderly women can maintain an exercise regimen over the long term. ${ }^{33}$ More research is required to fully understand the interplay between regular physical activity, such as strength training, functional independence, and psychological wellbeing.

\section{Exercise and bone}

One of the most important roles of exercise in elderly women is its potential to maintain bone integrity. This paper is not meant to be a com- prehensive review of the impact of aging and exercise on bone mineral density or osteoporosis as this has been reviewed extensively elsewhere. ${ }^{5960}$ Instead, it is intended to highlight some of the issues concerning the impact of strength training on bone integrity in elderly women.

Osteoporosis affects one in four women over the age of 50 and nearly half by the age of 75 and may be inevitable in some women depending on their diet and exercise habits in their younger life. ${ }^{61}$ Postmenopausal women are the group at highest risk for osteoporosis. Osteoporosis is a condition of low bone density such that susceptibility to low trauma fractures (typically wrist, vertebrae, and hip) is greatly increased. A recent comprehensive population study of hip fractures in two million Canadians $^{62}$ indicated that there are about 20000 hip fractures annually in Canada, with women accounting for $75 \%$ of the total. This figure is increasing rapidly and will almost double in the next 20 years as the population ages. Debilitating osteoporotic fractures of the spine are also at epidemic proportions. The huge personal, social, and economic costs of osteoporosis make it imperative that effective preventive and therapeutic strategies be developed.

The two main determinants of hip fractures are bone density and increasing falls. One of the most effective ways of combating the decline in bone density and decreasing the risk of falls in women who may be susceptible to the disease or already have it, is through weight bearing exercise. There is a tendency for fallers to be older and have lower muscular strength than non-fallers or infrequent fallers. ${ }^{63}$

Relatively few studies examining the effect of weight bearing exercise on bone density have included older subjects and these have produced equivocal results, largely because of methodological problems such as small sample size. However, it has been clearly shown that immobilisation induces the greatest reported rate of bone loss, greater even than that caused by a total loss of oestrogen. ${ }^{64}$ Furthermore, Alekel et $a l^{65}$ found that the combined contribution of total body weight and lifetime physical activity to bone mineral density is much greater in postmenopausal women than premenopausal women, particularly for the proximal femur, indicating that activity is particularly important for postmenopausal women.

Most researchers have been unable to prove that weight bearing exercise increases bone density in middle aged and elderly men and women; however, many have found that such exercise prevents or reduces the bone loss seen

Table 1 Benefits of regular exercise

Increase in exercise capacity, muscle strength, and flexibility Decrease in mortality from cardiovascular disease

Decrease in resting heart rate and blood pressure

Decrease in bone loss through weight bearing exercise

Decrease in bone loss
Improved lipid profile

Decreased percentage of body fat

Improved carbohydrate metabolism

Weight control

Increase in perceived wellbeing and self image

Improved cognitive function and reaction time

Decreased anxiety, insomnia, and depression

Adapted from Rohan. ${ }^{73}$ 
in non-exercisers. ${ }^{586066-68}$ Recently, Martin et $a l^{69}$ found that strength training resulted in an increase in bone mineral density of the lumbar spine and a trend towards improvement at the hip in women aged 65 to 75 years.

Exercise prescription for elderly people has typically focused on cardiovascular training and stretching. However, aerobic activities such as walking or running lack lateral and twisting movements and may not induce high enough strain levels to sufficiently maintain bone density. ${ }^{60}$ Further research is required to determine if an aerobically based exercise programme can be designed to include sufficient bone loading. At the present time, however, strength training seems to be the exercise mode of choice for maintaining bone integrity in elderly women.

\section{Considerations when designing exercises for elderly women}

Increased physical activity in elderly people, especially women, raises three important issues. Firstly, improving the adherence to a physically active lifestyle requires the assistance of behavioural scientists. This can be either through direct intervention or through research that can help elderly people to identify and overcome impediments to physical activity. Secondly, many elderly women have diseases that limit their physical ability. It is the job of the exercise scientist to prescribe exercise that is both efficacious and safe. Finally, with increased physical activity in elderly people, the number of injuries may increase. ${ }^{70}$ It is a paradox for exercise prescription for elderly subjects that the types of exercise such as strength training that have shown to result in the greatest gains in strength, function, and maintenance of bone integrity are also the type most likely to cause fractures and injury. The development or exacerbation of joint symptoms with exercise is obviously a potential barrier to strength training in elderly women. Both clinicians and patients commonly think that weight bearing exercise produces joint symptoms; however, existing evidence suggests that well regulated exercise does not produce or exacerbate these problems. ${ }^{71}$

Although elderly women may have potential limitations for exercise and although there is a potential increased risk of injury with increased activity, the benefits of regular exercise (table) far outweigh the potential drawbacks. The positive influence of physical activity is apparent for all age groups, but the most dramatic differences in functional ability and psychological health are seen within the senior population. Sherman et $a l^{2}$ found that women aged 75 years or older who were more active were more independent and lived longer than their inactive cohorts.

There are several strategies available for targeting less active people, including elderly women within the population:

- Set physical activity targets for particular groups who are at higher risk of a sedentary lifestyle
- Plan facilities, schedules, and other aspects of the social and physical environment to minimise potential barriers to increased participation

- Encourage women in their middle years to become and remain highly active. This offers long term protection against osteoporosis and cardiovascular disease and can significantly reduce the national health care bill for older adults

- Target older women, especially those who live alone as a result of widowhood, divorce, or separation. Women may live longer than men but they experience more limitations

- Consider low cost and accessible physical activity opportunities and facilities for those within lower income and educational brackets. $^{74}$

\section{Summary}

Many healthy elderly women are at, or near to, functionally important strength related thresholds and so have either lost or are in danger of losing the ability to perform some important everyday tasks. ${ }^{75}$ There is much research still to be done on the influence of exercise on strength, function, bone mineral density, and psychological health in elderly women. Current research in the field has shown that there are many advantages to strength training with elderly women. The most important of these are the maintenance of bone mineral density (and the consequent reduction of hip fractures) and functional independence. However, the long term effectiveness of strength training on these variables has yet to be established. Additionally, further research is required to determine if there are other modes of exercise that can elicit the same improvements in functional dependence and bone integrity as seen with strength training.

Barriers to physical activity are still a problem for many elderly women. They need to be identified and strategies to overcome them must be put into place. Continuing physical activity is so important to older women, not only because they make up a significant portion of the elderly population, but because the decline in physical activity and the subsequent increase in incidence of chronic illnesses are much more apparent in this population.

1 Gill TM, Williams CS, Tinetti ME. Assessing risk for the onset of functional dependence among older adults: the role of physical performance. $f \mathrm{Am}$ Geriatr Soc 1995;43:603-9.

2 Manton KG, Corder LS, Stallard E. Estimates of change in chronic disability and institutional incidence and prevachronic disability and institutional incidence and preva1984 and 1989 National Long Term Care Survey. $f$
lence rates in the US elderly population from the 1982 , Gerontol 1993;48:s153-66.

$3 \mathrm{Katz}$ S, Brach LG, Branson MH, et al. Active life expectancy. $N$ Engl $\mathfrak{f}$ Med 1983;309:1218-24.

4 Kemper $P$. The use of formal and informal home care by the disabled elderly. Health Serv Res 1992;27:421-51.

5 Spector WD, Katz S, Murphy JB, Fulton JP. The hierarchical relationship between activities of daily living and instrumental activities of daily living. fournal of Chronic Diseases 1987;40:481-9.

6 Fitness Directorate Health Canada. Active living and health benefits and opportunities. FDHC, 1994.

7 Shephard RJ. Physical activity and aging. Croom Helm: London, 1978: 268-91.

8 Anderson SF. An historical overview of geriatric medicine: definition and aims. In: Pathy MSJ, ed. Principles and practice of geriatric medicine. London: Wiley, 1985: 7-13. 
9 Ashworth JB, Reuben DV, Benton LA. Functional profiles of healthy older persons. Age Aging 1994;23:34.

10 Evans A and Meredith B. Exercise and nutrition in the eld erly. In: Munro HN, Danford DE, eds. Nutrition, aging and the elderly. New York: Plenum Press, 1989: 89-128.

11 Brooks SV, Larsson L, Woledge R, Schultz AB. Impairments in the structure and function of skeletal muscle with aging. Med Sci Sports Exerc 1994;26:s27.

12 Weir LT, Jackson AS, Ayers GW, Stutevill JE. Determinate of male and female longitudinal changes in $\mathrm{VO}_{2} \max$. Med Sci Sports Exerc 1994;26:s35.

13 Nadel ER, DiPietro L. Effects of physical activity on functional ability in older people: translating basic science findings into practical knowledge. Med Sci Sports Exerc 1995;25:s36.

14 Van Den Hambergh CEJ, Schouten EG, Van Staveren WA Van Amelsvoort LG, Kok FJ. Physical activities of noninVan Amelsvoort LG, Kok FJ. Physical activities of nonin-
stitutionalized Dutch elderly and characteristics of inactive elderly. Med Sci Sports Exerc 1995;27:334-9.

15 Green H, Milne A, Rauta I, Eldridge J, Wilmot A, Levy G General Household Survey 1986. London: HMSO, 1989.

16 Skelton DA, McLaughlin AW. Training functional ability in old age. Physiotherapy 1996;82:159-67.

17 Foster VL, Hume GJ, Byrnes WC, et al. Endurance training for elderly women: moderate vs low intensity. $\mathcal{f}$ Geronto 1989;44:M184-8.

18 Denh MM, RA Bruce. Longitudinal variations in maxima oxygen intake with age and activity. $\mathcal{f}$ Appl Physio 1972;33:805-7.

19 Nakamura E, Moritani T, Kanetaka A. Biological age versus physical fitness age. Eur f Appl Physiol 1989;58:778-85.

20 Brown WF, Strong MJ, Snow R. Methods for estimating number of motor units in biceps-brachialis muscle and number of motor units in biceps-brachialis muscle and
losses of motor units with aging. Muscle Nerve 1988;11: losses of

21 Hicks AL, Cupido CM, Martin J, Dent J. Muscle excitation in elderly adults: the effect of training. Muscle Nerve 1992 15:87-93.

22 Piscopo J. Fitness and aging. New York: Wiley, 1985: 96-151.

23 Vandervoort M, McComas AJ. Contractile changes in opposing muscles of the human ankle joint with aging. $f$ Appl Physiol 1986;61:361-7.

24 Aniansson A, Sperling L, Rundgren A, Lehnberg E. Muscle function in 75-year-old men and women: a longitudinal study. Scand F Rehab Medil Med Suppl 1983;90:92-102.

25 Cook PN, Smith-Exton AN, Brocklehurst JN, LempertBarber SM. Fractured femurs, galls and bone disorders. $R$ Coll Physicians Lond 1982;16:45-9.

26 Young A. Exercise physiology in geriatric practice. Acta Medica Scandinavica 1986;711(suppl):227-32.

27 Sipila S, Suominen H. Knee extension strength and walking speed in relation to quadriceps muscle composition and speed in relation to quadriceps muscle composition and

28 Rantanen T, Sipila S, Suominen H. Muscle strength and history of heavy manual work among elderly trained women and randomly chosen sample population. Eur $\mathcal{F}$ Appl Physiol 1993;66:514-7.

29 Voorips LE, Lemmink KAP, Van Heuvelen MJG, et al. The physical condition of elderly women differing in habitual physical activity. Med Sci Sports Exerc 1993;25:1152-7.

30 Simonsick EM, Lafferty ME, Phillips CL, et al. Risk due to inactivity in physically capable older adults. Am f Public Health 1993;83:1443-50.

31 Klitgaard H, Mantoni M, Schiaffino S, et al. Function, morphology and protein expression of ageing skeletal muscle: a cross-sectional study of elderly men with different training backgrounds. Acta Physiol Scand 1990;140:41-54.

32 Taunton JE, Rhodes EC, Wolski LA, et al. The effect of Taunton JE, Rhodes EC, Wolski LA, et al. The effect of land-based and water-based fitness programs on the aged 65-75 years. Gerontology 1996;42:204-10.

33 Rhodes EC, Martin AD, Taunton JE, et al. Effects of on year of resistance training on strength and bone density in elderly women. Med Sci Sport Exerc 1995;27:s21.

34 Morganti C, Nelson M, Fiatarone $M$, Crawford B, Economos C and Evans W. Strength improvement with progressive resistance training in older women. Med $S_{c}$ Sports Exerc 1994;26:s31.

35 Pyka G, Lindenberger E, Charette S, Marcus R. Muscle strength and fiber adaptations to a year-long resistance training program

36 Hunter GR, Treuth MS, Weinsier RL, Kekes-Szabo T, et al. The effects of strength conditioning on older women's ability to perform daily tasks. $\mathcal{f}$ Am Geriatr Soc 1995;43 756-60.

37 Connelly DM, Vandervoot M. Improvement in knee extensor strength of institutionalized elderly women after sor strength of institutionalized elderly women after
exercise with ankle weights. Physio Can 1995;47:15-23.

38 Kovanen V, Sipila S, Elorinne M, Alen M, Suominen H. Effects of intensive physical training on muscle fiber charEffects of intensive physical training on muscle fiber char-
acteristics in elderly women. Med Sci Sports Exerc 1994;26: s115.

39 Fiatarone, MA, EC Marks, ND Ryan, CN Meredith, LA Lipsitz, WJ Evans. High-intensity strength training in nonagenarians $\mathcal{F} A M A$ 1990;263:3029-34.

40 Laforest S, St-Pierre DMM, Cyr J, Gayton D. Effects of age and regular exercise on muscle strength and endurance. Eur f Appl Physiol 1990;60:104-11.

41 Aloia JF, Cohn AH, Ostuni JA, Cane R, Ellis K. Preventio of involutional bone loss by exercise. Ann Intern Med 1978;89:356-8

42 Rikli R, Busch S. Motor performance of women as a function of age and physical activity level. Med Sci Sports Exerc 1986;41:645-9.

43 Cauley JA, Petrini AM, LaPorte RE, et al. The decline of grip strength in the menopause: relationship to physical activity, estrogen use and anthropometic factos. Fournal of Chronic Diseases 1987;40:115-20.

44 Baylor AM, Spirduso WW. Systematic aerobic exercise and components of reaction time in older women. $\mathcal{F}$ Gerontol 1988;43:121-6.

45 Spirduso WW. Reaction and movement time as a function of age and physical activity level. 7 Gerontol 1975;30:435-40.

46 Spirduso WW, Clifford P. Replication of age and physica activity effects on reaction and movement time. $\mathcal{F}$ Gerontol 1978;33:26-30.

47 Chapman EA, Vries HA, Swezey R. Joint stiffness: effects of exercise on young and old men. $\mathcal{F}$ Gerontol 1972;27:218 21.

48 Buchner DM, Wagner EH. Preventing frail health. Clin Geriatr Med 1992;8:1-17.

49 Fiatarone MA, O'Neill EF, Ryan ND, et al. Exercise training and nutritional supplementation for physical frailty in very elderly people. $N$ Engl f Med 1994;330:1769-75.

50 Sauvage LR, Myklebust BM, Crow-Pan J, et al. A clinica trial of strengthening and aerobic exercise to improve gait and balance in elderly male nursing home residents. $A m \mathcal{F}$ Phys Med Rehabil 1992;71:333-42.

51 Skelton DA, Young A, Greig DA, Malbut KE. Effects of resistance training on strength, power and selected functional abilities of women aged 75 and over. $7 \mathrm{Am} \mathrm{Geri-}$ atr Soc 1995;43:1081-7.

52 Clark DO. The effect of walking on lower body disability among older blacks and whites. Am $\mathcal{F}$ Public Health 1996; 86:57-61.

53 MacRae PG, Asplund LA, Schnelle JF, et al. A walking program for nursing home residents: effects on walk gram for nursing home residents: effects on walk endurance, physical activity, mobili

54 Duncan JJ, Gordon NF, Scott CB. Women walking for health and fitness: how much is enough? $\mathcal{F} A M A 1991 ; 266$ 3295-9.

55 Brown DR. Exercise, fitness and mental health. In Bouchard C, Shephard RJ, Stephens T, Sutton JR, McPherson BD, eds. Exercise, fitness and health: a consensu of current knowledge.

56 Taylor CB, Sallis JF, Neelde R. IThe relation of physical activity and exercise to mental health. Public Health Rep 1985;100:195.

57 Bozoian S, McAuley E. Strength training effects on subjective well-being and physical function in the elderly. Med Sci tive well-being and physical

58 Bravo G, Gauthier P, Roy PM, et al. Impact of a 12-month exercise program on the physical and psychological health exercise program on the physical and psychological health

59 Martin AD. Osteoporosis: a geriatric public health issue. Topics in Geriatric Rehabilitation 1995;10:1-11.

60 Martin AD, Houston CS. Osteoporosis, calcium and physical activity: a review. Can Med Assoc f 1987;136:587-93.

61 Armstrong AL, Wallace WA. The epidemiology of hip frac tures and methods of prevention. Acta Orthop Belg 1994;60:85-101.

62 Martin $\mathrm{AD}$, Silverthorn KG, Houston CS, et al. The incidence of fracture of the proximal femur in two million
Canadians from 1972 to 1984 . Clin Orthop 1991;266:11118.

63 Dalsky GP, Fehling PC, Fenster J, Judge J, King M. Balance testing and falls in healthy older adults. Med Sci Sports Exerc 1994;26:s61.

64 Mazess RB, Whedon GD. Immobilization and bone. Calcif Tissue Int 1983;51:105-110.

65 Alekel L, Clasey J, Fehling P, Lee K, Stillman R. Regiona bone mass in pre vs post menopausal women: contribution of body weigh

66 Grove KA, Londeree BR. Bone density in postmenopausal women high impact versus low impact exercise. Med Sci Sports Exerc 1992;24:1190-4

67 Michel BA, Lane NE, Bloch DA, Jones HH, Fries JF. Effect of changes in weight bearing exercise on lumbar bone mas after age fifty. Ann Med 1991;23:397-401.

68 Peterson SE, Peterson MD, Raymond G, Gilligan C, Checovich MM, Smith El. Muscular strength and bone desity with weight training in middle-aged women. Med Sci Sports Exerc 1991;23:499-504.

69 Martin AD, Rhodes EC, Willis S, et al. Effect of progressive strength-training on bone mineral density of elderly strength-training on bone mineral density

70 Caspersen CJ, Kriska AM, Dearwater SR. Physical activity epidemiology as applied to elderly populations. Baillieres
Clin Rheumatol $1994 ; 8: 7-27$.

71 Coleman EA, Buchner DM, Cress ME, et al. The relationship of joint symptoms with exercise performance in older adults $\mathcal{F}$ Am Geriatr Soc 1996;44:14-21.

72 Sherman SE, D'Agostino RB, Cobb JL, Kannel WB. Does exercise reduce mortality rates in the elderly? Experience
from the Framingham Heart Study. Am Heart $\mathcal{f} 1994 ; 128$ : 965-72.

73 Rohan I. Benefits and risks of exercise in elderly patients. Canadian fournal of Continuing Medical Education 1994;9: 49-62.

74 Canadian Fitness and Lifestyle Research Institute. Progres in prevention: popular physical activities. CFLRI, 1996.

75 Young A, Skelton DA. Applied physiology of strength and power in old age. Int $\mathcal{F}$ Sports Med 1994;15:149-51. 